\title{
Mentoring in Teacher Education
}

PHOTO REDACTED DUE TO THIRD PARTY RIGHTS OR OTHER LEGAL ISSUES 
Mentoring in Teacher Education 
(C) Crown copyright 2008

RR Donnelley B54191 02-08

ISBN 978-0-7053-1128-1

HM Inspectorate of Education

This material may be copied without further permission by education authorities and education institutions in Scotland for use in school self-evaluation and planning.

The report may be produced in part, except for commercial purpose, or in connection with a prospectus or advertisement, provided that the source and date thereof are stated. 


\section{Contents}

Foreword

1. Introduction 2

1.1 The Context 2

1.2 Objectives 3

1.3 Methodology 6

2. Outcomes and impact of mentoring for newly qualified teachers

3. Current practice 9

3.1 How were mentors chosen? 9

3.2 What do mentors do? 10

3.3 How effective is mentoring? 13

3.3.1 The views of NQTs 13

3.3.2 The views of mentors 14

3.3.3 Organisation of support at school and EA level $\quad 15$

3.3.4 Use of resources 18

3.3.5 Professional development and benefits for mentors 20

4. Conclusions 22

5. Aspects for improvement 23

Annex 1 An approach to mentoring in the USA

Annex 2 Research on informal learning in early teacher 26 development 


\section{Foreword}

Support provided to newly qualified teachers in Scotland has attracted interest from education systems across the world. The Scottish Government has made significant investment in resources since 2002. Well-managed and supported induction experiences should enable new teachers to provide education of the highest standards for Scotland's children and young people.

Good quality mentoring in schools makes an important contribution to developing the professional skills of new teachers and ensuring the best quality learning experiences for pupils. New teachers benefit from this mentoring as they work towards the Standard for Full Registration. High quality continuous professional development can only take place with commitment from schools, education authorities and teacher education institutions to developing effective mentoring.

HMIE has evaluated the effectiveness of ways in which new teachers are supported. We have found that they are well supported during their first year of teaching. In particular, we have seen many examples of good practice where EAs provided well-coordinated programmes of continuing professional development. We recognised the importance of mentors' interpersonal skills in how they both challenge and support new teachers.

This report identifies good practice across Scotland and internationally and the impact that mentoring is having. It also identifies areas where provision can be improved. These improvements are necessary to maximise the effectiveness of mentoring in teacher education and the quality of Scotland's future teaching force.

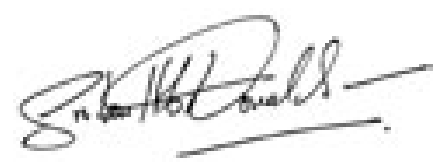

Graham Donaldson

HM Senior Chief Inspector of Education

February 2008 


\section{Introduction}

\subsection{The context}

At all stages of teacher education, mentoring is an acknowledged part of learning and developing new skills. In initial teacher education (ITE), student teachers learn from experienced class teachers in primary and secondary schools. In the induction scheme, newly qualified teachers learn professional skills and strategies from experienced colleagues. Mentoring is also an appropriate way for experienced teachers and managers to acquire management and leadership skills that can then lead to posts with wider responsibilities.

All newly qualified teachers in Scotland are required to complete a period of probation before being awarded full registration as a teacher with the General Teaching Council for Scotland (GTCS). Scottish-trained, newly qualified teachers (NQTs) are eligible for a guaranteed one-year teaching post with a Scottish local authority. This scheme has been in operation since August 2002 and is known as the Teacher Induction Scheme. The scheme ${ }^{1}$ makes a number of provisions for NQTs which include:

- a maximum class commitment time, equal to $70 \%$ of that of a full-time teacher, with considerable time set aside for professional development ${ }^{2}$;

- access to the services of an experienced teacher who will provide support and act as a mentor; and

- 0.1 FTE funding per NQT to local authorities for the provision of a mentor.

In August 2006, there were 1809 primary teachers and 1745 secondary teachers within the Teacher Induction Scheme.

1 www.scotland.gov.uk/Publications/2006/11/30104626/1

2 Further advice and guidance is available at www.gtcs.org.uk. and, www.gtcs.org.uk/ probationweb 


\subsection{Objectives}

This review focused on the mentoring of NQTs in primary and secondary schools.

The main objectives of the review were to:

- identify the factors which contribute to good practice in mentoring in this context;

- describe good practice in mentoring of NQTs and disseminate it through the report and otherwise;

- evaluate how well the resources allocated to mentoring are used; and

- make recommendations for improvements in mentoring practice.

What is meant by the term "mentoring"?:

There is no one universally accepted definition.

However, definitions of mentoring and related concepts were provided by Ellen Moir and Janet Gless from the New Teacher Centre at the University of Santa Cruz in May 2006 during their visit to Scotland.

1. Peer Coaching involves a relationship between two or more professional learners which enables them to share concerns and experiences and embed new knowledge or skills in their practice.
Frequently, those involved have similar professional interests and find the relationship to be of mutual benefit. The relationship may take the form of a network, perhaps evolving from another professional development experience. The process may be short term or long term and may be appropriate for colleagues who are teaching the same stage, are in the same department, have recently taken up new posts or are preparing for further promotion. Teachers often identify their own peer support, and training is not usually necessary. 
2. Mentoring is a more structured, sustained relationship for supporting professional learners at the early stage of their career, through a career transition or when facing a particular challenge. For example, newly qualified teachers, supply and returning teachers or recently appointed headteachers can benefit from a mentor. The mentor is normally a more experienced colleague with knowledge of the needs and professional context of the other person. The process is usually time defined and has a significant emphasis on developing the less experienced colleague's instructional skills and classroom practice. Mentoring is most effective when mentors are selected for their knowledge and expertise and given training in mentoring skills, adult learning, and the ability to identify and communicate best practices.
3. Specialist Coaching is a more structured and sustained relationship to help develop a particular aspect of the professional learner's practice. It enables professional learners to review and define existing practice, to develop and extend skills and to explore and introduce alternative strategies. It is of benefit to practitioners at any stage of their career. The specialist coach is normally a professional who has particular expertise as a coach but does not need specific subject knowledge, as the process focuses on the agenda of the person being coached. Coaches require training in effective coaching skills, and in many cases may have gained accreditation.

National CPD Team 
Developing mentoring and coaching skills in education

This is of national interest in the field of continuing professional development for teachers. The notion that teacher education should be viewed as a continuum is widely accepted. TEls offer a range of courses which include the development of skills in the process of mentoring. The relevant skills include the following.

Coaching/mentoring skills to be developed throughout the continuum of teacher education

- Observing practice

- Asking questions

- Giving advice

- Giving feedback

- Instructing
- Listening to understand

- Making suggestions

- Offering guidance

- Paraphrasing

- Reflecting

- Summarising

- Telling

Common elements of all coaching/mentoring relationships include:

- a learning conversation

- reflection and sharing

- agreed outcomes

- focus on learning and teaching

- mutual benefit

- confidentiality

National CPD Team 


\subsection{Methodology}

Fieldwork and evidence gathering took place between September 2006 and June 2007. The range of approaches included school visits and interviews with recently appointed NQTs, their mentors and headteachers. Schools from half of the 32 Education Authorities were represented in the fieldwork. Inspectors interviewed key staff in all seven teacher education institutions (TEls) and a sample of education authority officials responsible for the continuing professional development (CPD) of NQTs. A literature review of research and practice on mentoring in teacher education in Scotland, the UK and internationally also informed the review and its findings. Throughout this task, members of the HMIE team gathered and took account of the views of stakeholders on what they considered to be good practice and on how effectiveness could be improved.

The report includes a number of short sections and annexes of illustrative material derived from international practice, research and other sources. These are found in the introduction and at the end of the report. 


\section{2 \\ Outcomes and impact of mentoring for newly qualified teachers}

NQTs had a positive perspective on the effectiveness of mentoring and how this approach had helped develop them as teachers. They expressed a high degree of satisfaction with the clearly defined roles and duties of their mentors and the additional pastoral support they provided.

Education authorities provided well-planned and appropriately focused professional development opportunities for NQTs. These opportunities were well matched to the stage of development and needs of the new teachers. Systematic planning of NQT meetings also gave new teachers scope to learn from one another through sharing their experiences across schools.

Mentors made effective use of formal documentation such as guidance from the GTCS and the Standard for Full Registration to support NQTs. They used these documents for benchmarking progress and planning lesson observations. At induction, Initial Teacher Education profiles were most helpful to NQTs and school staff when they clearly identified areas for improvement based upon tutor evaluations and self-assessment by the NQT.

The effectiveness of mentoring was directly related to the quality of feedback from mentors to NQTs on how they could improve their practice. Some courses offered by TEls on mentoring were having a positive impact on how mentors provided feedback, and thereby on the experience of NQTs. Relationships between mentors and NQTs were positive and supportive overall. Many NQTs were confident about seeking and acting upon advice from mentors. They reported that their practice had improved. 
Often, staff other than mentors provided useful support that had features of mentoring and could be regarded as informal mentoring. This was particularly commonplace in primary schools, particularly for staff teaching at the same stage as the NQT, and within secondary school subject departments. This sort of engagement fostered good relationships between NQTs and a range of school staff.

Overall, approaches to mentoring were impacting positively on the experiences and professional development of newly qualified teachers. 


\section{Current practice}

\subsection{How were mentors chosen?}

Most mentors in primary schools held promoted posts. In a small number of cases, the headteacher served as mentor. More commonly, the position of mentor was held by a depute headteacher, or by a principal teacher in schools where this post existed. In secondary schools, the position of mentor was held in most cases by a principal teacher. Senior managers coordinated support, particularly where schools had more than one NQT.

In a small number of cases, EAs advised schools that mentors should not normally hold line management responsibility for NQTs. A number of mentors and NQTs acknowledged the potential conflict of interest between line management and mentor roles. Others held the view that mentors ought to be line managers. In secondary schools, mentors were usually, but not always, specialists in the same subject as the NQT.

Headteachers often selected mentors for their previous experience in supporting colleagues, their well-developed interpersonal qualities and skilled teaching practice. However, there were a small number of instances where NQTs were placed with teachers who were insufficiently experienced and skilled in mentoring. Some headteachers and other promoted staff saw deployment in the mentoring role as an opportunity to develop and demonstrate the leadership skills of the staff concerned.

The level of experience of those currently serving as mentors in schools varied considerably. Most mentors had two or three years experience in the role. Some had no earlier experience of mentoring and others as much as five or more years of experience. 


\subsection{What do mentors do?}

The duties undertaken by mentors were, in most cases, outlined clearly in school or EA guidelines. The guidance provided in GTCS documents helped mentors and NQTs to develop their understanding and expectations of support strategies.

Mentors discussed CPD needs with NQTs in the initial stage of their induction. In many cases, these needs had been clearly identified in the ITE profile provided by the university where NQTs had completed their initial teacher education.

All mentors arranged regular meetings with NQTs to discuss the progress of the NQT and to address any concerns. NQTs felt particularly well supported when they had opportunities to meet at least once each week at a regular time and had the opportunity to contribute to the agenda. During meetings, mentors and NQTs arranged and evaluated class observations and planned and reviewed a range of CPD activities. They also discussed and ensured the completion of the interim and final GTCS profiles.

Some mentors met informally with NQTs on a more frequent, often daily, basis. They provided helpful pastoral support for NQTs. The NQTs valued such opportunities. Some schools had identified additional times in the week in which NQTs and mentors could opt to meet informally in this way. In other cases, many mentors were often prepared to give of their own time freely to respond to the needs of the NQTs. Overall, mentors regularly acted as a critical friend to NQTs and supported them in developing skills and confidence.

In most cases, mentors themselves carried out most observations of NQTs, with some observations being undertaken by another member of staff, usually the headteacher. In a small number of cases, an officer of the authority or a member of staff of another school also acted as observer. 
In the best practice, mentors actively encouraged NQTs to take part in a wide range of development opportunities. These opportunities included pre-arranged observation visits to other classes in the school and visits to other schools. In some cases, mentors themselves modelled a lesson for the NQT. Mentors often arranged opportunities for NQTs to develop their own awareness of the work of colleagues in pupil support or other areas of the school and to take part in the wider life of the school by serving on working groups or by leading clubs or activities.

In a small number of cases NQTs did not make appropriate progress towards the standard for full registration. Mentors provided prompt indications of such lack of progress to senior managers and EA officers. They worked with senior management staff and EA officers to provide appropriate, well-targeted support for this small number of NQTs who were experiencing difficulties. 
An example of good practice in

St Vincent's Primary School, East Kilbride, South Lanarkshire

St Vincent's Primary School was inspected as part of a national sample of primary education.

The depute headteacher provided exemplary support in her role as mentor for NQTs.

In particular, she:

- maximised opportunities for the NQT to be exposed to good practice within the school and to learn from other schools;

- made clear what was expected of the NQT in meeting the needs of the pupils in her class and shared school policies and programmes;

- developed effective working relationships with all staff, parents and pupils;

- shared her skills as a classroom practitioner very effectively through modelling very good up-to-date learning and teaching practices for the NQT;

- encouraged the NQT to be reflective and self-critical in her own practice;

- managed and used time very effectively to provide evaluative feedback and challenge on how the NQT could improve her teaching and impact upon pupils' learning;

- gave appropriate emphasis to support and challenge including how to engage effectively with parents, and in wider aspects of the work of the school such as effective liaison with the parish priest; and

- supported the NQT effectively to develop confidence in the sharing and celebration of pupils' achievements with parents and the wider community. 


\section{Signpost to improvement in selection and roles of mentors}

- Schools select mentors who are skilled, experienced practitioners, who have well-developed interpersonal skills and demonstrate leadership qualities.

- Mentors provide well-judged support to NQTs and have appropriate expectations of them.

- Mentors have a good understanding of their role and duties to support and challenge NQTS.

- Mentors foster effective professional relationships with NQTS and seek support from senior managers and EAs as appropriate.

\subsection{How effective is mentoring?}

\subsubsection{The views of NQTs}

Overall, NQTs were very positive on their experiences during their first year of teaching and gave many examples of the ways in which their practice had improved as the year progressed. They considered that the effectiveness of mentoring was directly related to the professional relationships developed between themselves and their mentors. NQTs regarded the personal attributes of mentors as key to the success of the working relationship and described them as supportive, empathetic, encouraging and approachable.

The support provided through weekly meetings and discussions allowed for reflection and planning of next steps. NQTs appreciated the careful planning of the lesson observations by mentors and the supportive feedback that they provided. It was the view of the NQTS that such good quality feedback was the key element to improving their practices. NQTs also thought that the mentors helped them to set realistic targets for development and were both sensitive and helpful in the regular reviews of the progress being made to meet these targets. 
In a small number of instances, NQTs were less positive about their experiences. They perceived deficiencies including the following.

- Targets which had been set for their own development could have been more systematic and progressive.

- Their practice would have been improved had they received greater challenge from the mentor.

- They had been given inappropriate advice following classroom observations.

\subsubsection{The views of mentors}

Mentors regarded mentoring as an important responsibility, believed they were effective in their role, and found the experience of mentoring a rewarding one. They thought they had created an appropriate balance between pastoral care and support, and the level of challenge for NQTs. Mentors gave clear accounts of ways in which NQTs acted upon their advice and were making progress in developing skills as teachers. They found it beneficial when another promoted member of staff undertook an occasional lesson observation and confirmed that the NQT was making appropriate progress.

Almost all mentors were positive about the level of demand on their time. A very small number found the regularity of and preparation for weekly meetings a pressure. In secondary subject areas, mentors often carried out their mentoring role in addition to their regular duties associated with responsibilities of their promoted post. While they found this to be demanding, they did not perceive it to be an unreasonable burden. 


\section{Signpost to improvement in the effectiveness of mentoring}

- Mentors demonstrate a wide range of interpersonal skills to establish and sustain positive, professional relationships with NQTS.

- Mentors provide well-targeted support.

- Mentors provide systematic, progressive and challenging feedback.

- Mentors give balanced attention to pastoral support and to challenge on how to improve practice.

- NQTS take action on the advice they are given.

\subsubsection{Organisation of support at school and EA level}

Mentors spent a considerable amount of time in fulfilling their supportive role. Time for mentoring was used flexibly, particularly in large secondary schools with groups of NQTs and in small primary schools with few staff. Promoted staff found effective ways to resolve difficulties with staffing and class cover.

Almost all mentors were promoted staff. While they often had the necessary skills to be effective mentors, their wider remits were also demanding. Planning formal mentoring meetings was, at times, a challenge due to competing priorities. NQTs found the rescheduling of meetings at short notice frustrating. As a result, a small number felt less well supported as the mentor was not sufficiently accessible.

Education authorities provided well planned and appropriately focused professional development opportunities for NQTs. These were usually well matched to the stage of development and needs of the new teachers. Systematic planning of the content of NQT meetings also provided scope for new teachers to learn from one another through sharing their experiences. However, EAs were not sufficiently consistent in scheduling NQT training events to avoid clashes with school in-service days.

EAs had made good progress in seeking feedback from NQTs and evaluating their experiences. However, TEls had little or no input to CPD for NQTs. There remained headroom for EAs and TEls to work collaboratively in providing more CPD for mentors and NQTs. 


\section{An example of well-focused CPD for NQTS}

East Renfrewshire ran a core programme for all NQTs with monthly meetings on broad topics including child protection, parents' evenings, classroom behaviour, inclusion, interview skills, Curriculum for Excellence, equality and fairness. This was supplemented by a further optional programme. The topics covered included: managing self; how to be heard without shouting; enterprise; values and citizenship; dyslexia; Assessment is for Learning; motivating boys and girls; national priorities; How good is our school?; health promotion and project leadership.
Schools also ran their own programmes, for which the EA provided a strong lead and direction, to ensure breadth and provide a year in which key aspects were not duplicated and local/sector relevance was maintained. Specific aspects were therefore covered at school level with staff, usually mentors delivering them. These aspects included: self evaluation, behaviour support; learning support; ICT training; pupil support; shadowing staff; personal and social education; interviews and meeting with past probationers. There was some variety in key aspects and specific emphases, in line with the context of the school.

\section{Seeking feedback}

Scottish Borders had improved procedures over the last few years using feedback from NQT end of year questionnaires and a focus group of NQTs.
NQTs now each had a second year teacher as a 'buddy'. Joint events involving buddies and the NQTs allowed for discussions and sharing of experiences. Feedback from NQTs also contributed to improved documentation relating to the system of probationer support. 
An example of effective education authority support and intervention

Fife used funding to deploy four experienced promoted staff as "probationer supporters". The probationer supporters were allocated a quadrant of the authority and had responsibility for the support to NQTs in all secondary and primary schools in that area. This included liaison with mentors. The probationer supporters were funded 0.1 FTE out of their school to oversee support in their area of the authority. This involved undertaking school visits and observations of teaching and telephone contacts with headteachers, mentors and NQTs. The remit was to monitor the effectiveness of support and to ensure that teachers requiring support were identified at an early stage.
The EA introduced further stages of reporting in October and in February, prior to the interim report and prior to the final report. At these stages, the school evaluated the performance of NQTs using a four point scale: very good, good, fair and "causing concern". EA staff reported that the introduction of these further evaluative stages helped identify NQTs requiring further support or EA intervention at an early stage. Their past experience had shown that schools were reluctant to identify "cause for concern" at the interim stage as this indicated failure. The schools had been more willing under the new arrangements to indicate a "fair" evaluation, which triggered the provision of appropriate support.

\section{Support In Schools}

City of Edinburgh had introduced the role of School Induction Manager (SIM) in each school. The EA provided annual training for SIMs. Some good examples included well-coordinated school CPD for groups of NQTs. SIMs provided guidance and support to mentors who were new to their role. CPD opportunities were appropriately matched to the needs of the NQTs. Examples of topics included how support for pupils worked in a school, how the school related to parents and aspects of inter-agency working. SIMs carried out lesson observations to help confirm the work done between the NQT and mentors. 
While NQTs appreciated the wide range of informal support they received from colleagues generally, some NQTs felt they would have benefited from more structured opportunities to meet and network with other NQTs.

Research undertaken by TEls can provide helpful insights into developing appropriate support to NQTs. Some examples are provided in Annex 2.

\section{Signpost for improvement in the organisation of support}

- Schools manage time for mentoring effectively to suit the needs of the NQT and the context of the school. They create opportunities for NQTs to network with one another.

- Mentors who are also senior managers prioritise mentoring activities effectively.

- EAs provide appropriately focused and well-planned developmental programmes for NQTS.

- TEls and EAs work collaboratively to provide CPD for mentors and NQTS.

\subsubsection{Use of resources}

The use of funding for mentors (0.1 FTE) to carry out their mentoring duties was readily identifiable in primary schools. This was less clear in secondary schools due to more complex staffing and timetabling arrangements within and across subject departments. Time for NQTs (0.3 FTE) to undertake preparation and reflection, and to take part in CPD activities remained constant, in line with Scottish Government policy guidance, throughout the school year. 
Mentors and NQTs believed it was not necessary to have a 0.3/0.7 split constantly throughout the year Many mentors and NQTs would have preferred more flexible use of time in line with each individual NQT's development. In particular, they felt more time to work together was required at the induction stages. They felt it would be beneficial to allow NQTs to have greater class contact time as the year progressed in preparation for having full-time class commitment in their first year as a fully registered teacher. In many schools, NQTs were encouraged to participate in wider school activities during the later months of the school year. While this was valuable experience, it was sometimes coupled with a lessening of focus and challenge from mentors in further developing classroom practice at this stage.

Overall, the current arrangements were too prescriptive to support fully appropriate individual professional development for all NQTs in preparation for year two.

The ITE profile prepared by universities was potentially a key resource for NQTs' development. Schools needed clear information from TEls about NQTs' individual strengths and development needs, built up over a period of time. NQTS usually shared their ITE profiles promptly but this was not always the case. Headteachers, in particular of primary schools, found that having early access to detailed ITE profiles was important when allocating NQTs to classes.

Mentors and other school staff found the information in most profiles to be helpful in general terms. However, individual profiles ranged from comprehensive and thorough to vague and lacking in detail.

Headteachers reported a few cases where comments in the ITE profile did not match well to the skills of the NQT. 


\section{Signpost for improvement in the use of resources}

- Stakeholders have the freedom and capacity to use time flexibly to meet the professional development needs of each individual NQT effectively.

- Mentors use time for mentoring to keep a sustained focus on the level of challenge for NQTS to ensure classroom practice continues to improve throughout the year.

- Mentors and NQTs plan well-targeted support based on comprehensive and accurate ITE profiles.

- Headteachers make use of ITE profiles to place NQTs effectively.

\subsubsection{Professional development and benefits for mentors}

Most mentors took part in CPD opportunities provided by EAs. They were enthusiastic about developing mentoring skills. The development of mentoring in the education system contributed positively to capacity building and good quality experiences for pupils.

Many authorities ran training days for mentors early in the year to ensure that all mentors had a common understanding of their duties. Most training for mentors was based on procedures and administrative roles and duties to help NQTs fulfil the GTCS requirements. However, TEls also offered courses which included mentoring as a module, for example in Chartered Teacher programmes, and supported EAs in providing appropriate mentoring courses for teachers. These courses and some others offered to mentors by EAs took a more focused approach to developing the process of mentoring. However, such provision was not compulsory for all school staff supporting NQTs.

The Scottish Government provided local authorities with funding to promote mentoring and coaching in their schools. Authorities provided a wide range of relevant and effective CPD opportunities. However, EAs, mentors, headteachers, NQTs and TEls recognised the need to further develop skills in mentoring. They saw the benefits of developing interpersonal skills and the challenge aspect of mentoring. 
Many mentors described the benefits mentoring had brought to them. They believed they had become more self-critical and reflective in their own practices. Those who held promoted posts had developed improved skills in monitoring and evaluating practice. Specifically, they had developed skills in classroom observation. Professional dialogue with NQTs and other mentors enhanced their professional knowledge and kept them up to date with new developments in education. They valued the opportunity to develop leadership skills and credibility with colleagues. Experienced staff found the role of mentoring energising. However, learning the necessary new skills was not always systematic or progressive.

Headteachers thought the development of mentoring built capacity in their schools. They wanted more staff to benefit and learn through mentoring and coaching.

Headteachers serving as mentors in some small remote schools had set up informal "twinning" arrangements with colleagues in similar schools. This involved visits to "twin" schools and observation of NQTs. It provided the potential for greater consistency as well as the sharing of good practice.

\section{Signpost for improvement to professional development and} benefits to mentors

- EAs provide appropriate training for new and experienced mentors.

- TEls provide professional development opportunities for teachers based on the process of developing and applying mentoring skills.

- EAs and TEls work collaboratively to widen the range and uptake of mentoring courses.

- Mentors value their role and the credibility it offers them as individuals. They seek opportunities to progressively develop their mentoring and leadership skills.

- NQTS share insights and skills developed during ITE with mentors and school staff. 


\section{Conclusions}

Relationships between mentors and NQTs were positive and supportive overall. Approaches to mentoring were impacting positively on the experiences and professional development of newly qualified teachers.

Investment of resources has had a positive impact on the development of teachers. There were clear benefits to NQTs, mentors, school staff and pupils' experiences.

The combination of helpful guidance provided through GTCS documentation, TEl input to developing mentoring and the value placed on mentoring by the profession contributed significantly to the positive outcomes outlined in the report.

With further collaboration and evaluation, the already successful system can be further improved. 


\section{Aspects for improvement}

Schools were not always in a position to place NQTs with appropriately experienced staff who had the necessary skills for effective mentoring.

In some instances planning of formal mentoring meetings was less regular due to time constraints and competing priorities on the time of promoted staff. Schools needed to ensure that time allocated for mentoring NQTs was protected and changes to planned activities minimised. Education authorities should ensure CPD courses for NQTs do not coincide with in-service days for schools.

In a few instances NQTs were not sufficiently challenged to develop and improve their classroom practice. A sustained focus on developing teachers' skills in the process of mentoring would ensure sufficient challenge and progression in developing the practices of NQTS.

NQTs would benefit from having some full-time teaching experience towards the end of their induction year. Ways to maximise the flexible use of resources for the benefit of NQTs throughout the year and subsequently should be explored further.

TEls should improve their systems for ensuring the quality and consistency of the ITE profiles they provide. All stakeholders should stress the importance of NQTs sharing the ITE profiles with schools in good time to improve planning for their development and allocation to classes.

TEls were insufficiently involved in the continuing professional development of NQTS. They should continue to develop their involvement in providing courses for teachers on the process of mentoring. 


\section{Annex 1 An approach to mentoring in the USA}

New Teacher Center Santa Cruz

The New Teacher Center (www. newteachercenter.org) is an American centre of excellence which specialises in the induction of new teachers. It has an impressive track record of developing the skills of new teachers and achieving high retention rates among new teachers. The New Teacher Center (NTC) has considerable experience in this field and seeks to integrate policy, research, and practice related to induction. It started in 1988 in California as a project with a mentor-based teacher induction approach and now works in 32 states. It has some evidence on the effectiveness of its trained teachers in raising students' attainment.

The essential features of the mentoring model are:

- Mentors are selected from practising teachers using specific criteria. Positions are advertised by the NTC; applications or self-nominations are made and formal interviews held for selection.
- Mentors are trained and seconded from schools for a three-year period. The philosophy of three-year contracts is one of sustainability. During year one the mentors are trained in the skills of mentoring, and they become proficient during their second and third years of mentoring. By the third year the mentors have internalised their skills and learning and contribute to program development and leadership.

- Mentors mentor 12 to 15 beginning teachers each, across a number of schools, for two years. Mentors work with new teachers during the day and after school, observing practice and giving feedback, guiding lesson design, analysing student work, co-teaching, and setting professional goals.

- Mentors are engaged in professional learning during their three-year secondement. The professional learning has three components: explicit training in the pedagogy of mentoring and adult learning, participation in a weekly 
mentor professional learning community (Friday Forums), and a peer coaching relationship with another mentor.

- Mentors share the evidence of their new teachers' development at regular Friday meetings. This sharing was said to develop an important 'community of learning'. The 'Friday Forum' agenda was shared and leadership of the meeting was also a corporate responsibility. A range of strategies were used. For example, mentors worked with their coaching partners to complete a collaborative assessment log. This encouraged self-reflection and the identification of next steps in development. This was a technique known to the group as problem posed/problem solved. Also in pairs, mentors planned a shadowing experience to learn from one another in the field. The shared leadership, level of interpersonal and presentational skills of the mentors was of a high standard.

- The program coaches mentors in developing strong relationships with headteachers, lead teachers, and local authority personnel.

- Many find the experience of being a full-time mentor creates other career opportunities and advancement. During a 19-year period of developing the programme, many schools in California have gained members of staff who have trained as mentors. Principals and mentors report that the mentor training continues to have an impact on the culture of staff development in schools once mentors return to their posts or take up new positions. Mentoring skills continue to be valued and deployed. The growing number of schools with teachers trained in mentoring has improved capacity to sustain collaborative coaching even when schools no longer have beginning teachers.

The Executive Director, Ellen Moir, and Associate Director, Janet Gless, visited Scotland in May 2006 and delivered a number of seminars and workshops across Scotland. These were very well received by both education authority and university staff. 


\section{Annex 2 Research on informal learning in early teacher development}

The work of McNally, Boreham, Cope, Gray and Stronach (2004) explores the notion of informal learning in early teacher development. The main features of the informal learning experience for new teachers lie in the supportive environment.

Informal Learning in Early

Teacher Development (2004) Jim McNally, Nick Boreham, Peter Cope, Peter Gray, lan Stronach.

"Informal Learning" is a term devised to describe the important elements of support for new teachers which go beyond the more carefully structured support often planned for by schools, and government. Formal learning includes lesson observations, competence based agendas and meetings and also "next steps" meetings/targets. The researchers claim in this paper that different forms of learning take place. Interviews with student teachers and probationers indicate that learning takes place outside the formal structures of school. In particular, contact with school staff without formal responsibility for the beginner could prove to be fruitful. Often learning would also take place within school structures in the sense that line managers, departmental colleagues and scheduled meetings could also provide useful support, but often in a manner which could be described as informal, even friendly.

The "informal learning" contexts referred to by new teachers include ad hoc meetings in staffrooms and after-school clubs, and were often informal conversations. Much of what teachers know and do is tacit. Much is not seen by an observer and may not even be consciously acquired by the beginner. This may be why it eludes the researcher. 
From informal learning to identity formation: a conceptual journey in early teacher development. McNally J. (2006) Scottish Educational Review. Special Edition Teacher Education and Professional Development 37 (79-90)

This paper traces the development of an attempt to understand how teachers learn to teach from a vague grounded concept of informal learning through to identity formation. Drawing on ongoing research into beginning teachers in a Scottish context, it is argued that the early experience of teaching is characterised by emotionality and relationality rather than as a more cognitive or competence-related kind of professional learning. The conclusion is that progressive focusing on researching informal learning has been important in leading to a more robust theory of early professional learning in teaching, supported by a wider international literature, as a deeper process of personal change and an emergent self-as-teacher identity.

University of Stirling 
28 


\section{www.hmie.gov.uk}

\section{$£ 10.00$}

(C) Crown copyright 2008

RR Donnelley B54191 02/08

Further copies are available from

Blackwell's Bookshop

53 South Bridge

Edinburgh

EH1 1YS

Telephone orders and enquiries

01316228283 or

01316228285

Fax orders

01315578149

Email orders

business.edinburgh@blackwell.co.uk

Further information is available from:

HM Inspectorate of Education

Denholm House

Almondvale Business Park

Almondvale Way

Livingston

EH54 6GA

Tel: 01506600200

Fax: 01506600337

Email: enquiries@hmie.gsi.gov.uk 